\title{
Accountability for Effective and Efficient University Teaching
}

\author{
HAROLD M. GOOD* \\ BERNARD TROTTER**
}

\section{Introduction}

The universities and colleges of Canada are currently being asked to provide evidence that they are spending the large sums provided them both effectively and efficiently. The word "accountability" is being used as a short-hand expression for their responsibilities in this regard. But "accountability" is a woolly word and there is controversy over what it is that the institutions of higher learning can be held accountable for. Whatever it may be, it appears that it must be shown if continued public support is to be expected.

Trotter and Creet (3) have contributed to the controversy by maintaining that, apart from counting graduates of various kinds, there is little quantitative information which is useful in the process of universities accounting to government-that the main element of accounting to government should be by a clear demonstration that internal processes of accountability are working well at several levels of a hierarchy.

This argument does not play down the importance of the concept of accountability. It attempts rather to make it specific in different ways at different levels. The simple hierarchy as presented by Trotter and Creet (2) is illustrated in Figure 1. We should point out here that this approach to accountability in which a heavy line is drawn between the university and government, takes for granted a system of more or less autonomous university institutions which are self-governing in the sense that academic decisions are fully within the competence of the professoriate. This represents the normal case in Canada, so far as universities are concerned, but would not be true of many U.S. state universities.

It is not our purpose here to argue the merits of this approach to accountability. We do, however, think it useful to postulate it as a framework within which the kinds of accountability involved in the teaching process can usefully be explored.

To do this we must broaden the accountability at the bottom of the hierarchy to include more than just that of the professor to his institution. Professors interact with students and with peers in a scholarly discipline. So, at the teaching/learning interface there are at least five kinds of accountability to be kept in mind.

\footnotetext{
* Harold M. Good is Director, Ontario Universities Program for Instructional Development.

** Bernard Trotter is Head, Office of Academic Planning, Queen's University, Kingston.
} 


\begin{tabular}{|c|c|}
\hline \multicolumn{2}{|c|}{ A HIERARCHY OF ACCOUNTABILITY } \\
\hline DECISION & ACCOUNTABILITY \\
\hline $\begin{array}{l}\text { Level of spending } \\
\text { Method of distribution }\end{array}$ & $\begin{array}{l}\text { Government to electorate } \\
\text { to leglislature }\end{array}$ \\
\hline $\begin{array}{l}\text { Allocation within universities } \\
\text { Allocation within budget } \\
\text { units } \\
\text { Activity of individual } \\
\text { professor }\end{array}$ & $\begin{array}{l}\text { University to government } \\
\text { Unit (faculty, department) } \\
\text { to university } \\
\text { Professor to unit }\end{array}$ \\
\hline
\end{tabular}

Figure 1. A Simple Hierarchy of Accountability for University Systems.

Teacher to scholarship

Teacher to university

Teacher to student

Student to teacher

Student to self

These five kinds of accountability appear to us to be the most relevant to the teaching process and hence to our assigned topic of teaching in relation to the financing of higher education.

We will not, however, attempt to treat these five kinds of accountability individually. They are too closely interwoven to make this profitable. We shall deal with them under the two headings:

Systematization of teaching

Specialization in Time

We could put our approach to these topics in the form of a question: In general do universities in Canada, or rather their teachers since it is the teaching with which we are primarily concerned, present convincing evidence that they are examining carefully and systematically non-traditional alternatives to prevailing methods of organizing the teaching and learning process? We hope, in tackling this question, to make clear its relevance to the topic of accountability.

In attempting to answer this question we shall concentrate on what the professor does, or might do, and on the things which encourage or inhibit him in considering change. This 
emphasis recognizes the traditional autonomy of the university teacher in deciding what happens in "his" classroom and what "his" students are required to do to gain credit in "his" course. At the same time it emphasizes his critical position in the accountability hierarchy and his key position in controlling experimentation and change. Change must in a university be initiated by the teacher. Within an existing course structure he can do much on his own initiative but for wider change he must get the consent, and often the collaboration, of his colleagues. In the latter case the power of the majority of teachers to initiate or to prevent change is close to absolute. Power of this magnitude must be coupled with a high level of responsibility and an awareness that, ultimately, the accountability of the university itself is at stake.

\section{Systematization of Teaching}

The idea of applying systems methods to the educational process arose naturally as systems theorists looked for ways to extend ideas gained from operations research and industrial organization and production to other areas. The approach becomes even more logical with the availability of new technologies--television, computers, audio systemswhich allow instructional materials (in particular the individual professor's own voice and face) to be stored and repeated at will.

Unfortunately the new hardware came into use before systems methods were generally understood or applied in education. The result has been, overall, a poor record of accountability in learning to use new resources effectively. Overstated claims have reinforced the endemic hostility of academic communities to real or imagined threats from the external world. But when pressures of student numbers have left no other way, university professors have quite happily turned to large-scale use of closed circuit television in order to avoid repeating the same lectures. Much more rarely have professors explored the possible uses of television or other methods to improve the quality of their work regardless of the numbers involved. In many cases, however, once forced into using some of the newer techniques, ways are sought and found of improving what is presented to students. The overall result may or may not be better. But if quality and student satisfaction have been maintained without multiplying staff in proportion to student numbers, then a real achievement has to be acknowledged.

\section{Pressures for examining new methods}

There are reasons for thinking that we shall have to use technology even more widely and more wisely. Payment for professorial time takes up almost half of most university budgets. Now that universities are recruiting much more slowly than in the sixties there will be a very large bulge of relatively young staff expecting to progress through the ranks and up the salary curve for the next fifteen years while relatively few reach retirement age and relatively few are recruited at the bottom. So unless government grants increase by a good deal more than is needed to cover inflation, expected salary increases can only materialize if the same teaching activities are carried out by fewer staff. Obviously there are upper limits to this squeeze. But the individual professor, if he is going to do an effective job, and if he is not to be overworked beyond the point of endurance, will have to look much more seriously than he has before at alternative ways of helping students to learn. 
Nor are these immediate financial considerations the only pressures. With the continuing expansion of knowledge, the time required to keep up with one's field and to be active in scholarship increases. This has been one of the factors reducing effective student-teacher contact. It is a factor which will remain with us. But in a period of static or shrinking real resources, we can only accommodate to this pressure by reallocation of time. Here accountability to scholarship and to students are certain to come in to some measure of conflict. This provides a powerful pressure to consider every possible strategy for improving teaching and for saving effort at the same time, thus reducing the sharpness of the conflict.

The rapid growth of participatory democracy within our institutions of higher learning has also put added pressure on our resources, or read the other way, adds a further dimension to the urgency for efficient use of our principal resource-staff effort.

Finally, in this by no means exhaustive list of pressures toward examination of new strategies, we have an increased emphasis on the importance of education as a continuing process. This emphasis is coupled with the realization that many students now end their formal post-secondary education neither trained nor motivated to continue studying on an independent basis.

\section{Essential conditions for change}

If there are all these pressures toward re-appraisal of our current methods and examining new ones we might well ask what are the essential conditions for the development of new strategies. Basically, there are two. First, a willingness to look at objectives in a detached and critical way, and second, a willingness to reconsider allocation of effort in patterns which will assist in the achievement of these objectives. These conditions are easy to state and difficult to achieve. As we have pointed out in the introduction, they may be achieved only after a majority of staff in an institution have come to agree upon them.

\section{Some illustrative objectives and strategies}

So far we have spoken in very general terms. To make our approach clearer, and at the same time to propose changes which we think should be seriously considered, let us take a limited group of objectives and consider some possible strategies for achieving them. We offer these as illustrative approaches to certain problems, not as a fully systematized approach to teaching.

The objectives which we shall consider are:

1 Providing the student with a sound basis and capacity for continuing self-education.

2 Making full and effective use of student effort as a resource.

3 Ensuring that enough teacher effort is reserved for scholarship.

4 Ensuring the most effective teacher-student interaction.

We shall argue that these four objectives can be served by certain rather simple changes in emphasis in the teaching process.

If the emphasis on learning all one's life which one finds, for example, in the Report on Post Secondary Education in Ontario is valid, then it seems reasonable to argue that the success of a university or college education can be judged to a considerable degree on the extent to which it has motivated and trained students to work on their own. Motivation 
requires self-selected rather than imposed objectives. But, in how many courses is there a real effort to stimulate and assist the student to formulate his personal objectives in relation to a particular course? The ideal situation was described graphically by Mario Creet in the TUBS Report (1). He envisaged the "course" as being a cooperative project between teacher and learner each defining his objectives on his own behalf and in terms of the other: each as object acting on each as subject. The course is the medium through which this interaction takes place. Figure 2 is a slightly modified version of the Creet diagram.

The objectives of teacher and learner form the area within which content, method and evaluation define the specific course. The objectives are pooled rather than being separated. There are outcomes for both. The accountability of each to the other is realised through the mutual discussion of objectives.

The components of this scheme are not always absent from current courses, but neither are they always present. The question which should be asked is this. Would it be educationally profitable to spend an appreciable amount of time in a course trying to develop with students a plan which provides for shared objectives and agreed-upon strategies? It will certainly take time and effort on the part of both teachers and learners and it can therefore only be done by a trade-off between this approach, with its awareness of twoway accountability, and the value of some specific content which may have to be left out to provide time for development of well understood and shared objectives.

We incline to the view that this trade-off can often be a good one. Our major reason for holding this view is that better motivated students will make more effective use of the rest of the time. And this gain will offset loss of content, if, in addition to motivational emphasis on objectives, methods are used which require students to rely less on members of faculty for information transfer teaching. They are likely also to acquire study habits

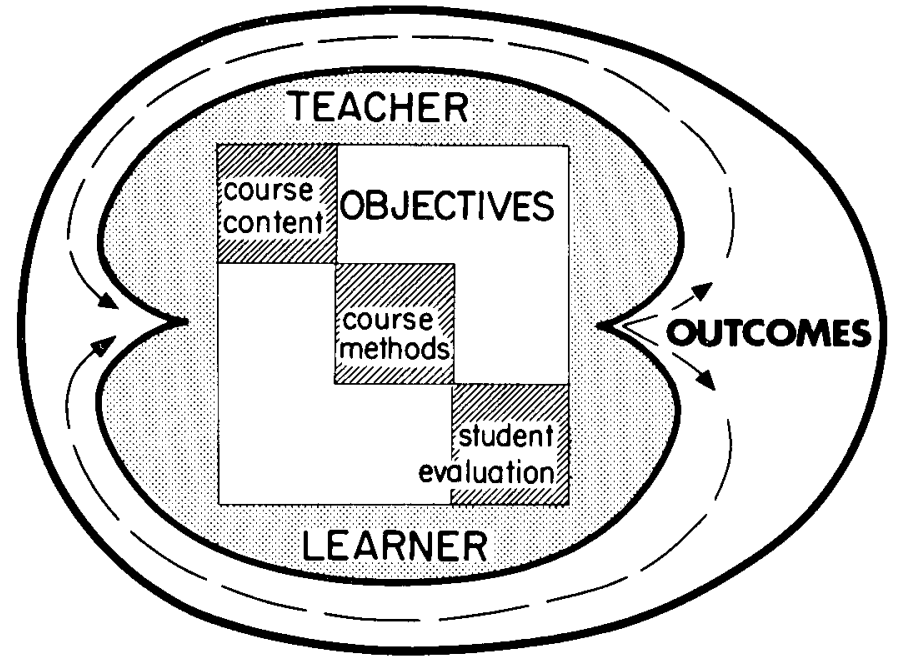

Figure 2. The University Course Seen as a Meeting Ground for Shared Objectives of Staff and Students. 
which prepare them for further education. Such an approach would also considerably increase the effectiveness of student effort as one of the resources of the system.

Let us now make an attempt to develop a strategy for the apparently impossible task of meeting our third and fourth objectives of providing more time for teachers to be scholars and simultaneously more time for direct teacher-learner interaction. This can logically be done only by identifying inefficiencies in our present system and then finding ways of eliminating them. We shall deal with only a single example of such inefficiency involving redundancy of effort.

The system, with its major components identified, can be represented as in Figure 3.

What we are concerned with is the central area of this figure-with the interrelations of actual time spent in the classroom with time spent in preparing teaching materials, and opportunities for increased efficiency based on redeployment of effort. Since we are concerned here with efficiency, we have used "output" in this diagram rather than the vaguer term "outcome" used in the previous figure.

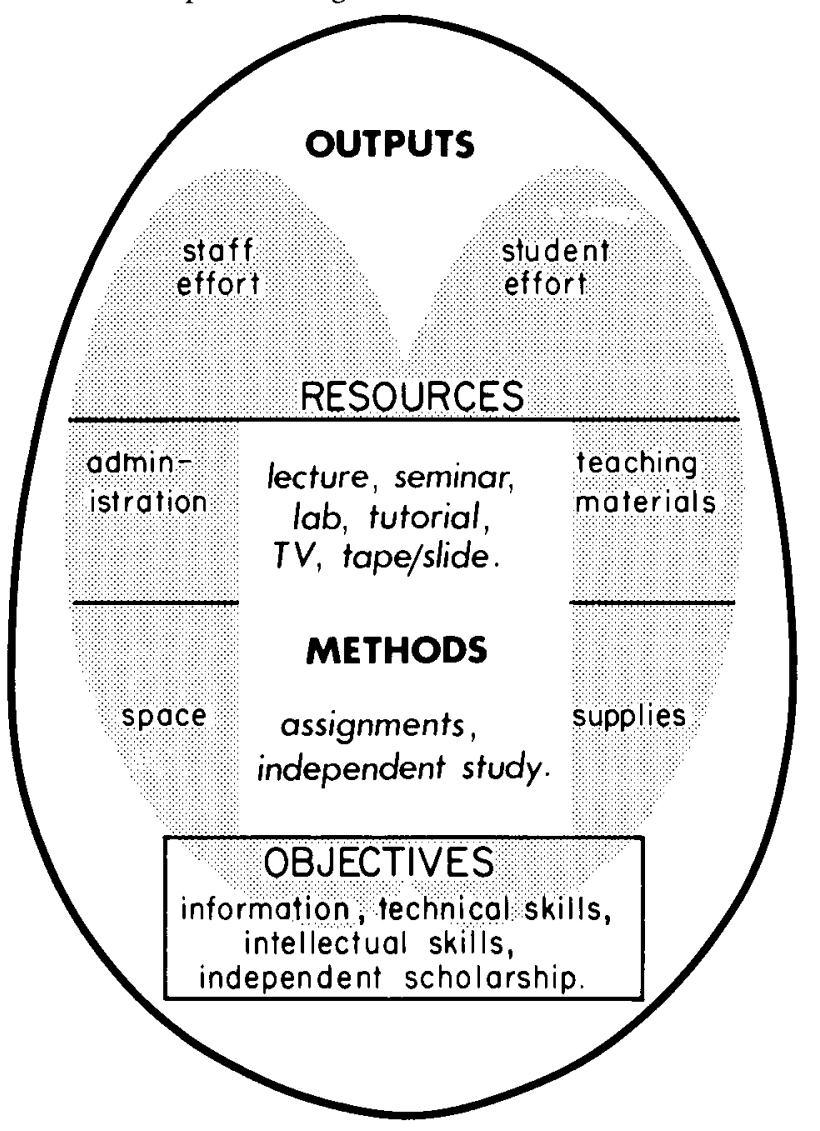

Figure 3. The "system" within which a specific course operates. The area of immediate concern is that involving staff effort, student effort, teaching materials, and the relation of these to methods. 
A university teacher, teaching by standard methods of lectures, tutorial groups and seminars is likely to have his teaching time divided roughly into four parts of preparation for, and presentation of, lectures and laboratory programs to one part of direct student contact. He, and his students, are fortunate if he can give this much time to personal attention to students. It is instructive to look at the implications of this division into preparation and presentation and personal contact in relation to large classes organized in different ways.

One of the results of our sharply increased student enrolments is that many of our classes have indeed become so large that many have felt that they had to be split into sections or alternatively into comparable courses having slightly different designations. If we consider the expenditure of effort in preparation and presentation and in personal contact in two models-one for a class of 1000 divided into five sections of 200 each, and the other for a single class of 1000 each with five professors assigned-we can see that the way in which the class is organized can have major implications for the efficiency of the use of the teacher effort.

These two problems of organization are shown graphically in Figure 4.

Thus by adapting the strategy of a large class, we have in this case cut redundancy in preparation and presentation and have achieved an increase of $2 \frac{1}{2}$ times in the effort available for preparation and presentation while at the same time an increase of 3 times in the time available for student contact. These "savings" might legitimately be divided between the teacher's scholarship and tutorial activities with his students.

This example is very simplified. We do not include time spent in co-ordinating the

\section{Preparation \& Presentation \\ $\bigcirc$ Personal Contact}

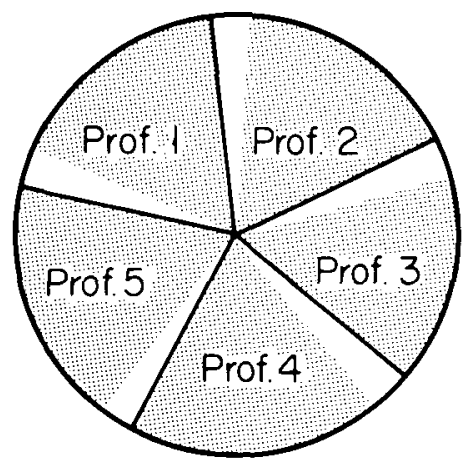

Class of 1000 in 5 sections:

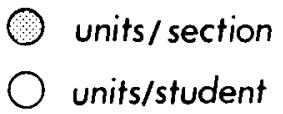

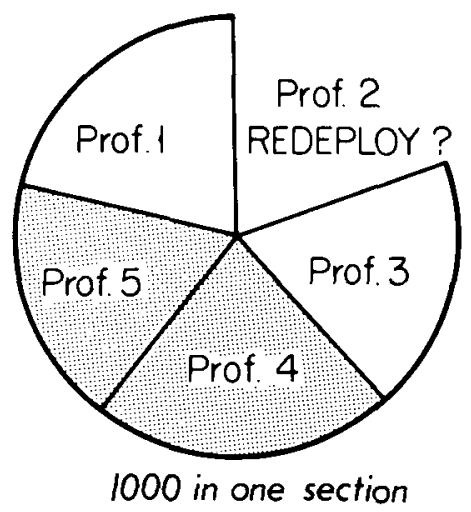

$\bigcirc$ units/section $\bigcirc, \bigcirc$ units/student

Figure 4. A comparison of the effective total time applied to preparation and presentation and to personal contact in two classes of 1000 organized in different ways. 
work of different professors, or in preparing effective programs for individualized attention. On the other hand, we do not include the potential additional savings from the use of permanent or semi-permanent instructional material such as tape-slide presentations, TV tapes, etc. Nor do we consider the obviously increased advantages of producing materials by inter-university cooperation. We believe, however, that accountability of teachers to students, and of teacher to the university, and of teacher to their scholarship, requires very critical study of the optimal way of deploying staff effort.

We are altogether aware that, in suggesting study of redeployment of faculty effort in these ways, we are questioning some of the most fundamentally held beliefs about what constitutes good teaching. We know some excellent teachers devoted to their students who believe that any change which reduced the amount of time they now spend in contact with all of their students would necessarily diminish the quality of their teaching and their students' learning. And we do not suggest that this represents overweening pride on their part. They may be right. Highly personalized teaching may be the best kind there is. It would be hard to prove either way in a particular case. But the argument today has to be about the optimum balance of effort directed in various ways. And the question which the traditional individualist professor has to answer is will a change in which preparation and presentation time is reduced overall result for the average student in a loss of quality large enough to offset the possible advantages to both students and faculty in the alternative strategy? Discussion about absolute rights and wrongs in these matters is futile. So long as argument against consideration of change rests on the dogma that "my students will suffer if they are deprived to any extent of me" there can be no real exploration of fruitful redeployment of effort.

\section{Specialization in Time}

In the previous section we suggested in effect that more specialization in function within the teaching part of a professor's effort might yield real dividends. We now wish to consider whether another aspect of specialization, namely specialization in time, might not also be developed further than it has been. In effect we are zeroing in on what we call the wheel spinning syndrome. This is shown graphically in Figure 5 which is based primarily on data in "The Ten O'clock Scholar?" by Trotter et al. (4)

Our argument is that if one divides a teacher's time into all the possible components parts of teaching, research, administration, public service-with each of these often subdivided into several discrete parts (and many teachers do have all the responsibilities represented here)-we must add a component which is the effort spent in moving to and adjusting to each new job as it comes along. This can be many, many times per day. When interruptions and changes of work reach a certain frequency (which varies, of course, for different individuals) or when work is fragmented as in a committee which considers an issue at widely spaced times, the productivity of the intervening time can be very near zero. Effort spent in not getting anywhere is wheel spinning.

One way to reduce wheel spinning is to increase specialization in time. We have already developed some examples of this. Sabbatical leave is a kind of specialization when the faculty member is relieved of teaching duties so that he can concentrate on study and research. It may be considered as an extension of normal duties-a period of reassignment 


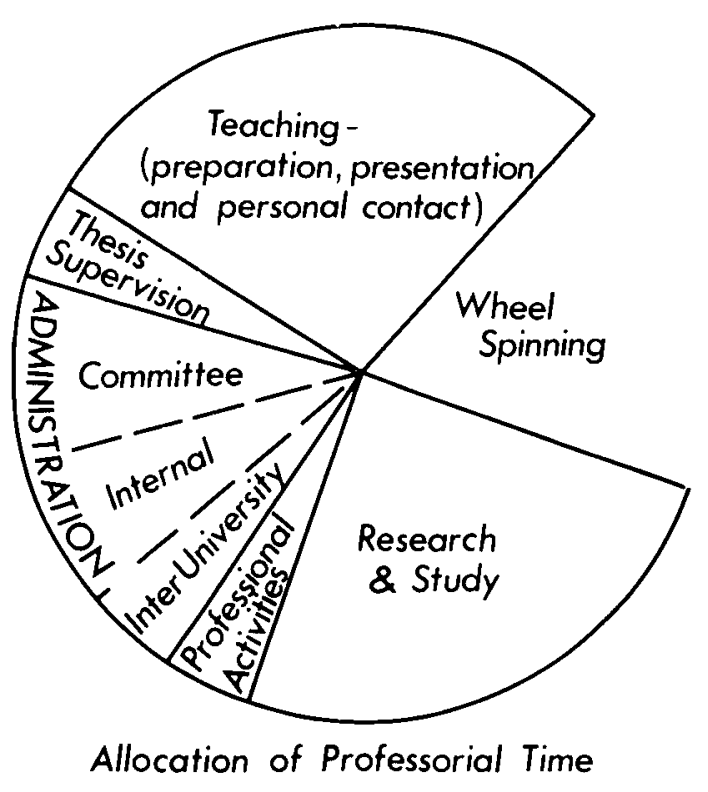

Figure 5. Allocation of professor time showing an allowance for "wheel spinning"-the inefficiency caused by too great a subdivision of responsibilities.

so to speak from regular teaching to other activities. So the principle of this kind of specialization is not altogether radical. Indeed, in many universities there are a few research stars who do relatively little undergraduate teaching and put most of their effort into research and graduate teaching. Similarly, faculty members who assume administrative duties as department chairmen, or faculty deans, frequently get relief from part of their normal teaching responsibilities. We propose an extension of the principle of temporary specialization to all members of faculty.

Individuals who prove themselves to be skilled in course development and in the preparation of materials could well be relieved of all other duties for the time necessary to complete the planning and "production" of a new course or the revision of an old one. Others might for a two or three year period carry more than a normal load of committee work on behalf of a department or a faculty with no other responsibilities other than study and research, so that they do not fall behind in their disciplines. They might, during this period, do some "guest" lecturing or tutoring in another faculty member's course, but would not be responsible for organizing any course or evaluating any students. They would be, for the time, "committee specialists." Such a procedure might well result in more effective and efficient committees. Nowhere is the "wheel spinning" syndrome more evident than in committees where most of the members are either apathetic-or what is worse-take up entrenched positions without the time to do their homework.

Specialization in committee work might do the university a real service by releasing much of faculty time and effort for more productive use. Committee specialists would be au courant with the work of their committees on a continuing basis and able to give sus- 
tained thought to the issue involved between meetings which is the secret of effective and efficient committees. It can be easily argued that the process of accountability should include evidence that the internal affairs of the university are conducted with as much concern for the effective use of resources as are the teaching and research activities. An argument which may find even more favor with teachers is that this may be the place to find some additional time for scholarship; critical appraisal of this kind of reallocation is very much in the self-interest of the teacher.

\section{Conclusion}

We believe that an awareness of the full range of accountabilities appropriate within a university or college must lead to an appreciation of the need for new strategies. But we are not satisfied that this awareness is currently well developed in Canada. In a recent article, Prof. Sheffield (5) has dealt comparatively with the issues of improvement of teaching in higher education. His article makes it clear that very much more attention has been given to systematic improvement of the quality of teaching at the British universities than is evident yet in Canada. But even in countries showing some concern and effort, he is less than satisfied. His general comments at the end of his survey (which covers Russia, Sweden, Germany, Denmark and the Netherlands) are worth quoting.

"I find myself wondering", he writes "if the schemes to which attention has been drawn do not tend towards over-emphasis on research, much of it on too small a scale to be significant and much of it of the reinvention-of-the-wheel variety. I think too, that many of the programs dwell overmuch on techniques and technology, and on experimentation and innovation-as if only the new were worthy. The alternative, for my taste, would be more stress on understanding the process of learning, the role of the teacher as an accomplice, and the attitudes, especially of caring, which are at the heart of good teaching."

We sympathize very much with efforts to improve conventional lectures, seminars, laboratories. We doubt, however, that these methods can be most effectively developed in the absence of informed evaluation of the now available alternatives. The professor who shows no curiosity about these or rejects them on the basis of uninformed prejudice, cannot be said to "care". And when it comes right down to it, that is what accountability is all about: proving that you do indeed care about using public money to the best possible advantage for students who come to the university for an education.

There is some evidence that concern for teaching is now being specifically rewarded in Canadian universities. It remains to be seen, however, whether there will be wide recognition of the possibility that good teaching and good scholarship can be served equally well by new ways of doing things. In the long run, the continued existence of Canadian universities as semiautonomous institutions will depend on the capacity of the professoriate to account in credible ways for the choices they make among the alternatives now available. 


\section{Notes}

1 Good, H.M. and Trotter, Bernard. "Frontiers in Course Development: System and Collaboration in University Teaching," Report of the Conference on Teaching University Biological Sciences, Jacksons Point, Ontario, May, 1971. Council of Ontario Universities. 1972.

2 Trotter, Bernard and Creet, Mario. "Counting is not Accounting," University Affairs, October, 1972.

3 Trotter, Bernard and Creet, Mario. "Accountability: Subjective Imperative," Proceedings of the 13th Annual Forum of the Association for Institutional Research, Vancouver. May, 1973.

4 Trotter, Bernard, McQueen and Hansen. "The Ten O'Clock Scholar? " CAUT Bulletin 21: 3 (January 1973), page 7 .

5 Sheffield, E.F. "Approaches (mostly elsewhere) to the Improvement of Teaching in Higher Education." Improving College and University Teaching XXI, 1. 